\title{
Integrated approach for predicting impacts of future climate and land use changes on macroinvertebrates in a Mediterranean catchment using GF, SWAT and HEA models
}

\author{
$\underline{\text { Jawairia Sultana }}^{a}$, Friedrich Recknagel ${ }^{a}$, Hong Hanh Nguyen $^{\mathrm{b}}$ and John Tibby \\ ${ }^{a}$ Department of Ecology and Evolutionary Biology, School of Biological Sciences, The University of \\ Adelaide, Australia \\ ${ }^{b}$ Leibniz-Institute of Freshwater Ecology and Inland Fisheries, Berlin, Germany \\ ${ }^{c}$ Department of Geography, Environment and Population, Sprigg Geobiology Centre, The University of \\ Adelaide, Australia \\ Email: jawairia.sultana@adelaide.edu.au; jawairiasultana@gmail.com
}

\begin{abstract}
Climate and land use changes are expected to alter flow and nutrient regimes in catchments affecting stream habitats and aquatic biodiversity. Scenario analysis by an integrated modelling approach may assist to better understand after-effects of such projected changes on biodiversity. This study aimed to quantify the impacts of climate and land use changes on the macroinvertebrate community of the Torrens river catchments, South Australia. Gradient forest (GF) determined average seasonal flow as main factor affecting macroinvertebrate assemblages in this catchment. A catchment model developed by the Soil and Water Assessment Tool (SWAT) was used to simulate flow under following scenarios: 1) future climate change scenario (RCP 8.5) based on six global circulation models, 2) hypothetical land use change scenario of deforestation over the next 30 years, and 3) scenario combining land use and climate change. Results of the future climate change scenario suggested decreased monthly flow due to declining precipitation and increasing air temperature, in contrast to the future land use change scenario of deforestation that predicted increased monthly flows. The combined future scenario to some extent suggested a trade-off between projected climate and land use changes but indicated dominating land use impacts due to deforestation resulting in increased runoff and higher flows. The Hybrid Evolutionary Algorithm (HEA) was used to model flow-driven abundances of GF-identified key species Hydrobiidae spp. and Tasmanocoenis tillyardi over 14 years at a representative stream site. The coefficients of determination $r^{2}$ of the HEA models ranged between 0.88 and 0.96. Results indicated Hydrobiidae spp. to be tolerant and adaptive to altered high flows under the future combined scenario by showing higher abundance as compared to individual climate change and land use change scenarios. In contrast, T. tillyardi has shown affinity to low flow conditions and decreased abundance in future combined scenario. The integrated modelling approach based on SWAT and HEA proved to be suitable for studying stream health under the impact of projected future climate and land uses.
\end{abstract}

Keywords: Climate change, land use change, gradient forest, SWAT, HEA, macroinvertebrates 
Jawairia Sultana, Integrated approach for predicting impacts of future climate and land use change on macroinvertebrates in a Mediterranean catchment using GF, SWAT and HEA models

\section{INTRODUCTION}

Worldwide, freshwater ecosystems are exposed to multiple stressors that adversely affect stream biota. Species diversity is declining due to climate change, urbanisation, intensive agriculture and other stressors affecting the water resources. These changes alter the physical and chemical characteristics of streams that result in loss of biodiversity and ecosystem services. Land use and climate change has shown an increased nutrient enrichment and varying flow trends affecting the overall river health (Nguyen et al. 2018, Shrestha et al. 2017, Walsh et al. 2005). Even though altered flow regimes have been widely discussed as an important variable affecting river ecosystems (Dewson et al. 2007, Domisch et al. 2017), only a few studies explored the impact on stream biota (Kakouei et al. 2018, Kakouei et al. 2017, Pyne and Poff 2017).

Among a variety of stream biota, macroinvertebrates are widely used as bioindicators by different river health monitoring programs due to their sensitivity to environmental conditions and ubiquitous distribution. A number of modelling approaches have been developed and applied to examine ecological impacts on stream biota (Baker and King 2010, Sonderegger et al. 2009). Despite these efforts, catchment managers face difficulty in communicating information from the database generated by river health monitoring programs. Most of the applied approaches are either limited to threshold analysis for updating water quality guidelines or biophysical models that evaluate changes in the environment (Peter Goonan 2012). To overcome these limitations an integration between bioindicator monitoring and different modelling approaches to predict river health is required.

Thus we proposed an integrated approach to develop and test a modelling framework which can be used to predict and monitor the status of river ecosystems under projected future conditions, saving time and cost. Our approach combines the inferential ecological models Gradient Forest GF and Hybrid Evolutionary Algorithm HEA with the process-driven hydrological model Soil and Water Analysis Tool SWAT to improve the understanding of complex eco-hydrological processes. This study was based on the following research questions: 1. What are the most important environmental stressors affecting the studied macroinvertebrate assemblages? 2. What are the indicator species affected by the most important environmental stressor? 3. How may projected variations in abiotic drivers (climate change and land use change) affect assemblages of selected indicator species?

\section{MATERIAL AND METHODS}

\subsection{Study Site and Data}

The study area comprises of Sixth creek, a sub-catchment of the Torrens River that covers an area of 4300 ha in the Mount Lofty region of South Australia. This sub-catchment is characterized by Mediterranean climate of dry summers and mild wet winters (Peel et al. 2007). It is associated with perennial stream flows that inhabits diverse macroinvertebrates with many rare, pollution sensitive and flow-dependent species (www.epa.sa.gov.au). This sub-catchment was selected as a case study because of its importance for water supply, long records of historical daily flows and near pristine conditions.

Macroinvertebrates and water quality data was provided by South Australian monitoring, evaluation and reporting Program (SA-MERP), that was established since 1994 to assess the river health of South Australian waterways. Flow data was obtained from existing gauging station at the same site macroinvertebrates data was collected. Future climate data was extracted from six Global Climate Models (GCMs) as mentioned in the Goyder Institute Water Research (GIWR) project developed for SA climate and run for high emission (RCP 8.5) and medium emission (RCP 4.5) scenario.

Associated considered related

\subsection{Modelling design}

Our integrated modelling approach for this study (Figure 1) started with the use of gradient forest (GF) for identifying the most important environmental stressor affecting the macroinvertebrate assemblages. Then two representative species among the most responsive species discovered by GF were selected as indicator taxa related to the identified stressor. GF is a regression tree based machine learning method. It uses bootstrap procedure to calculate predictor importance and identifies most responsive species to any gradient based on highest $\mathrm{R}^{2}$ weighted importance. GF was used using R package "gradientForest".

At the second step, the process-based hydrological model Soil and Water Assessment Tool (SWAT) was used to simulate future flow for the following 3 scenarios: 1) future climate change scenario based on six global circulation models, 2) hypothetical land use change scenario i.e forest to pasture over the next 30 years, and 3) scenario combining land use and climate change. SWAT is a river basin model that simulates catchment 
Jawairia Sultana, Integrated approach for predicting impacts of future climate and land use change on macroinvertebrates in a Mediterranean catchment using GF, SWAT and HEA models

processes such as surface runoff/infiltration, percolation, evapotranspiration, nutrient and sediment transport (Neitsch et al. 2011). This study used a well-developed SWAT model for the Sixth creek and further details on model calibration and validation can be found in Nguyen et al. (2019).

Finally, the simulated time series output from SWAT and indicator species from gradient forest were used for developing predictive models by the Hybrid Evolutionary Algorithms (HEA). HEA has been developed to evolve predictive models in form of simple IF-THEN-ELSE rules. It incorporates genetic programming (Koza 1992) to find the optimum structure in combination with differential evolution (Storn and Price 1997)to parameterize the fittest models. The $\mathrm{C}++$ version of HEA (Cao et al. 2013) was run on a Corvus supercomputer with a cyclic boot-strap scheme of 100 runs. The models with $\mathrm{r}^{2}>0.7$ were selected for further evaluation.

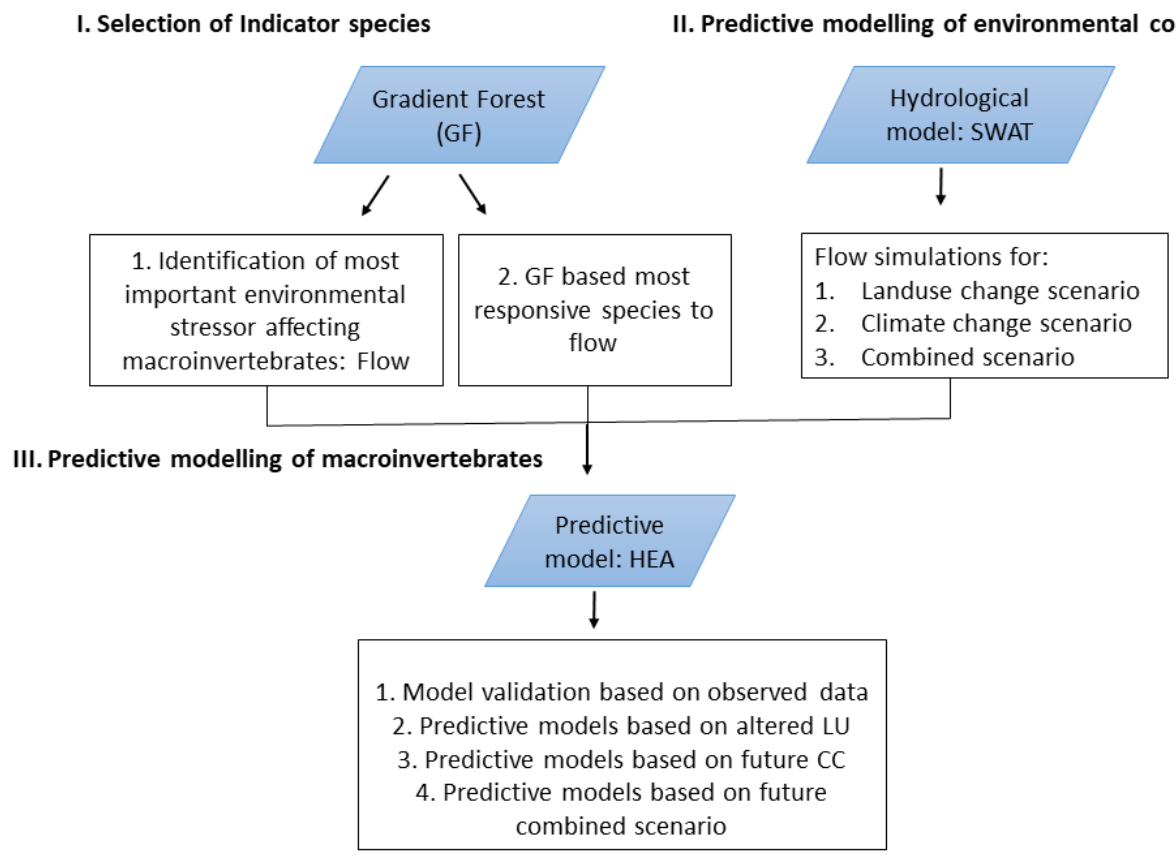

Figure 1. The overall modelling design

\section{RESULTS AND DISCUSSION}

\subsection{Identification of important stressor and most responsive species}

Among different environmental stressors, gradient forest (GF) determined average seasonal flows (ASF) as the most important factor affecting macroinvertebrates in the study area (Figure 2a). GF also identified the most responsive species to ASF (Figure 2b). Out of the most responsive species, two species were selected for predictive modelling i.e. Hydrobiidae spp. assuming its ubiquitous distribution irrespective of changing environmental or flow conditions (Davies et al. 2010) and Tasmanocoenis tillyardi due to its preference to still or slow flowing habitats (Gibbins et al. 2000). 
Jawairia Sultana, Integrated approach for predicting impacts of future climate and land use change on macroinvertebrates in a Mediterranean catchment using GF, SWAT and HEA models

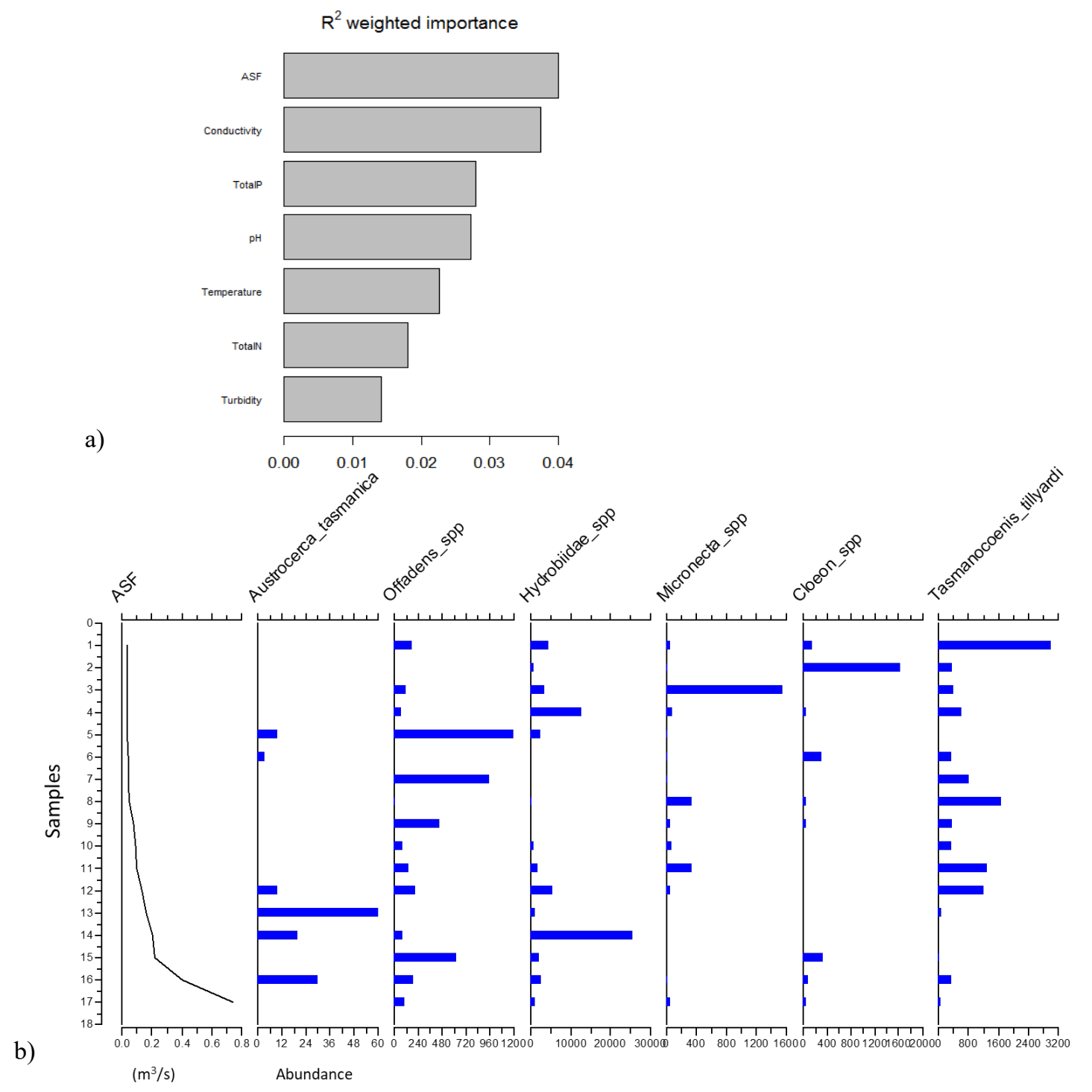

Figure 2. Gradient forest (GF) results: a) identifying Average Seasonal Flow (ASF) as most important variable affecting macroinvertebrates; b) abundance trends of six most responsive species in relation to ASF

\subsection{Hydrological model simulations for flow under future scenarios}

SWAT results are summarized as relative change to the baseline simulation using historic climate data (19812005) of six global climate models and constant land use (Figure 3). For scenario simulations, the highest relative increase in flow (14\%) was observed in land use change scenario which corresponds to highest decrease $(-12 \%)$ in climate change-induced flows. Sixth creek belongs to a forested catchment and future extensions of these land uses by pastures seemed to increase runoff that lead to ultimate high flows in receiving water bodies. The combined future scenario showed potential increasing trends in flow with largest increases (13\%) observed during late winters (Figure 3). Similar trend of higher flows were predicted in these catchments based on hypothetical deforestation scenario over the next 30 years (Nguyen et al. 2018, Shrestha et al. 2017) with land use change of greater concern as compared to future climate change. 
Jawairia Sultana, Integrated approach for predicting impacts of future climate and land use change on macroinvertebrates in a Mediterranean catchment using GF, SWAT and HEA models

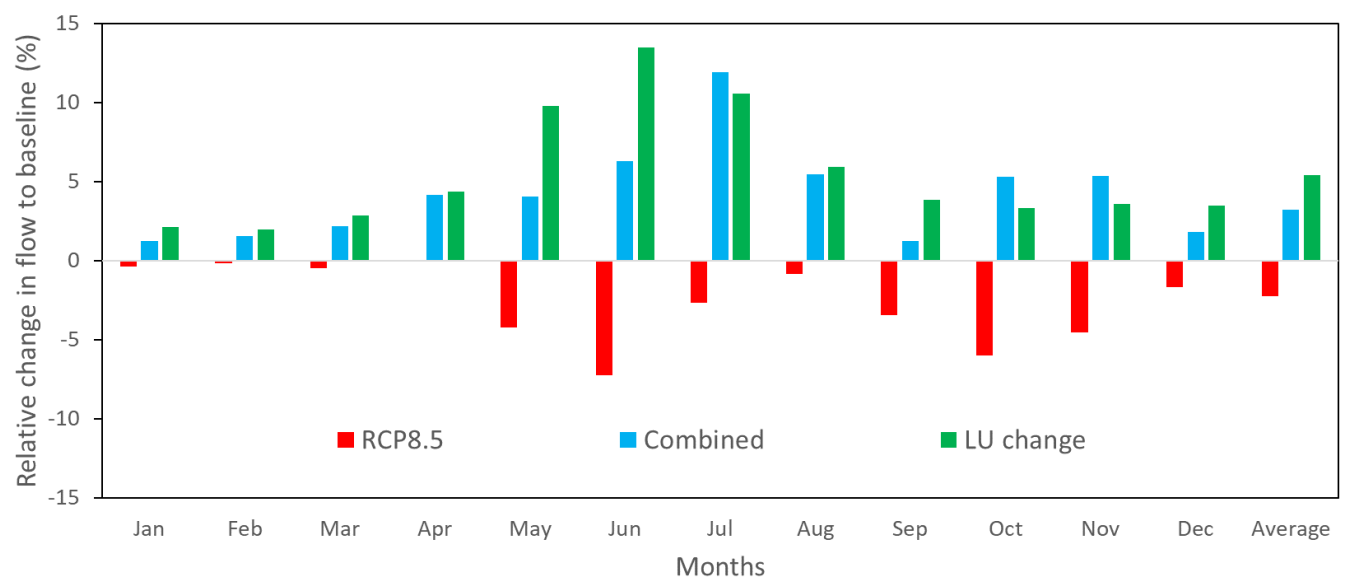

Figure 3. Soil and Water Assessment Tool (SWAT) results for relative change in mean monthly flow for climate change, land use change and combined future scenario compared to the baseline simulation for the time period 2016-2045.

\subsection{Impacts of climate and land use change on selected species}

The predicted changes in species abundance in relation to the observed baseline are shown in Figure 4. All these predictions were based on IF-THEN-ELSE-rules discovered by HEA, where validation was performed using observed data provided by South Australian Environmental Protection Authority (SA-EPA). The species abundance in relation to future flow conditions were different during individual scenarios and was species dependent. Hydrobiidae spp. appeared as tolerant or adaptive to future flow conditions with an increasing trend in all the simulated scenarios (Figure 4). In contrast Tasmanocoenis tillyardi has shown a decreasing pattern to the higher land use change-induced flows. A slight increase (7\%) in abundance of T. tillyardi in climate change scenario indicated some affinity to low flow conditions (Figure 4). Overall, Hydrobiidae spp. abundance displayed ubiquitous distribution in all the future altered flow conditions.

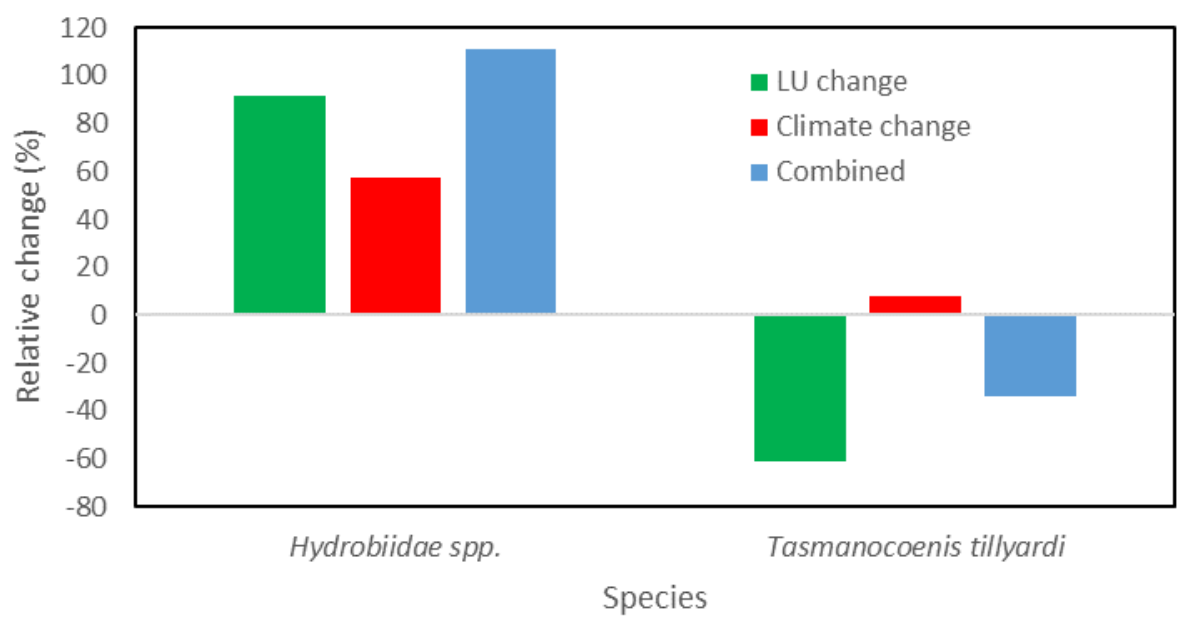

Figure 4. Hybrid Evolutionary Algorithms (HEA) results for relative change of selected macroinvertebrate species abundances of future scenarios compared to the baseline simulation for the period 2016-2045.

\section{CONCLUSIONS}

In this study, an integrated modelling approach was demonstrated to reveal the impacts of projected climate change and land use change scenarios on river biodiversity. It is applicable to any catchment system with community to species level consideration, enabling managers of informed decision and management. This approach can be useful to provide an insight in future habitat preferences of the targeted species. Following conclusion can be drawn from this specific study: 
Jawairia Sultana, Integrated approach for predicting impacts of future climate and land use change on macroinvertebrates in a Mediterranean catchment using GF, SWAT and HEA models

- Average seasonal flow is the most important factor affecting macroinvertebrate assemblages in these river catchments.

- Altered flow conditions for the individual and combined scenario simulations revealed highly speciesspecific responses.

- Flow tolerant species like Hydrobiidae spp. has shown an increased abundance at expense of other sensitive species of mayflies.

\section{REFERENCES}

Baker, M.E. and King, R.S. (2010) A new method for detecting and interpreting biodiversity and ecological community thresholds. Methods in Ecology and Evolution 1(1), 25-37.

Cao, H., Recknagel, F. and Orr, P.T. (2013) Enhanced functionality of the redesigned hybrid evolutionary algorithm HEA demonstrated by predictive modelling of algal growth in the Wivenhoe Reservoir, Queensland (Australia). Ecological Modelling 252, 32-43.

Davies, P.J., Wright, I.A., Findlay, S.J., Jonasson, O.J. and Burgin, S. (2010) Impact of urban development on aquatic macroinvertebrates in south eastern Australia: degradation of in-stream habitats and comparison with non-urban streams. Aquatic Ecology 44(4), 685-700.

Dewson, Z.S., James, A.B. and Death, R.G. (2007) A review of the consequences of decreased flow for instream habitat and macroinvertebrates. Journal of the North American Benthological Society 26(3), 401-415.

Domisch, S., Portmann, F.T., Kuemmerlen, M., O'hara, R.B., Johnson, R.K., Davy-Bowker, J., Bækken, T., Zamora-Muñoz, C., Sáinz-Bariáin, M. and Bonada, N. (2017) Using streamflow observations to estimate the impact of hydrological regimes and anthropogenic water use on European stream macroinvertebrate occurrences. Ecohydrology 10(8), e1895.

Gibbins, C., Jeffries, M. and Soulsby, C. (2000) Impacts of an inter-basin water transfer: distribution and abundance of Micronecta poweri (Insecta: Corixidae) in the River Wear, north-east England. Aquatic Conservation: Marine and Freshwater Ecosystems 10(2), 103-115.

Kakouei, K., Kiesel, J., Domisch, S., Irving, K.S., Jähnig, S.C. and Kail, J. (2018) Projected effects of Climate-change-induced flow alterations on stream macroinvertebrate abundances. Ecology and evolution 8(6), 3393-3409.

Kakouei, K., Kiesel, J., Kail, J., Pusch, M. and Jähnig, S.C. (2017) Quantitative hydrological preferences of benthic stream invertebrates in Germany. Ecological Indicators 79, 163-172.

Koza, J.R. (1992) Genetic programming: on the programming of computers by means of natural selection, MIT press.

Neitsch, S.L., Arnold, J.G., Kiniry, J.R. and Williams, J.R. (2011) Soil and water assessment tool theoretical documentation version 2009, Texas Water Resources Institute.

Nguyen, H.H., Recknagel, F. and Meyer, W. (2018) Effects of projected urbanization and climate change on flow and nutrient loads of a Mediterranean catchment in South Australia. Ecohydrology \& Hydrobiology.

Peel, M.C., Finlayson, B.L. and McMahon, T.A. (2007) Updated world map of the Köppen-Geiger climate classification. Hydrology and earth system sciences discussions 4(2), 439-473.

Peter Goonan, S.G., Clive Jenkins, Shaun Thomas, Matt Nelson, Tracy Corbin, Tavis Kleinig, Robyn Hill, Warwick Noble and Andrew Solomon (2012) The South Australian monitoring, evaluation and reporting program (MERP) for aquatic ecosystems: context and overview.

Pyne, M.I. and Poff, N.L. (2017) Vulnerability of stream community composition and function to projected thermal warming and hydrologic change across ecoregions in the western United States. Global Change Biology 23(1), 77-93.

Shrestha, M.K., Recknagel, F., Frizenschaf, J. and Meyer, W. (2017) Future climate and land uses effects on flow and nutrient loads of a Mediterranean catchment in South Australia. Science of the total Environment 590, 186-193.

Sonderegger, D.L., Wang, H., Clements, W.H. and Noon, B.R. (2009) Using SiZer to detect thresholds in ecological data. Frontiers in Ecology and the Environment 7(4), 190-195.

Storn, R. and Price, K. (1997) Differential evolution-a simple and efficient heuristic for global optimization over continuous spaces. Journal of global optimization 11(4), 341-359.

Walsh, C.J., Roy, A.H., Feminella, J.W., Cottingham, P.D., Groffman, P.M. and Morgan, R.P. (2005) The urban stream syndrome: current knowledge and the search for a cure. Journal of the North American Benthological Society 24(3), 706-723. 